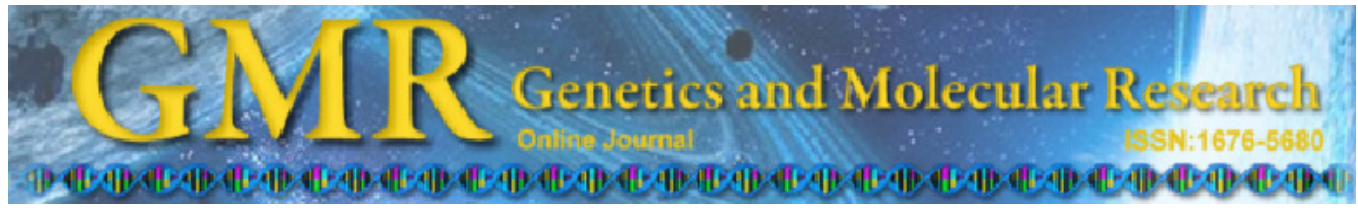

$\underline{\text { Research Note }}$

\title{
Single primer-based DNA amplification as a suitable and low-cost tool for assessing genetic diversity in mangrove crabs
}

\author{
F.B. Britto ${ }^{1,2}$, D.S.F. Mendes ${ }^{2}$, M. Ogawa ${ }^{3}$, I.H.A. Cintra ${ }^{4}$ and F.M. Diniz ${ }^{2}$ \\ ${ }^{1}$ Departamento de Ciências da Natureza, Universidade Federal do Piauí, \\ Bom Jesus, PI, Brasil \\ ${ }^{2}$ Embrapa Meio-Norte, Teresina, PI, Brasil \\ ${ }^{3}$ Departamento de Engenharia de Pesca, Universidade Federal do Ceará, \\ Fortaleza, CE, Brasil \\ ${ }^{4}$ Departamento de Ciências Aquáticas, \\ Universidade Federal Rural da Amazônia, Belém, PA, Brasil
}

Corresponding author: F.B. Britto

E-mail: fbbritto@yahoo.com

Genet. Mol. Res. 10 (4): 4084-4092 (2011)

Received May 20, 2011

Accepted October 5, 2011

Published November 9, 2011

DOI http://dx.doi.org/10.4238/2011.November.9.2

\begin{abstract}
We used single primer-based DNA markers to assess genetic variability of the mangrove crab, Ucides cordatus, collected from four different localities from Pará to Santa Catarina States in Brazil (almost $5000 \mathrm{~km}$ distant). Five primers were chosen based on the consistency of the amplified bands and the polymorphism of each locus. A total of 78 loci were amplified in 76 samples; high polymorphism rates were detected in the entire sample $(80.8 \%)$ and within each locality (73.5-79.5\%). Analysis of molecular variance demonstrates significant differences between localities $(P<0.001)$; however, the $\Phi_{\text {ST }}$ value (0.078) indicates a low level of genetic differentiation, which suggests that $U$. cordatus larvae can spread over large distances. The variation was distributed among the samples, and most of it was attributed to differences among individuals within localities. Cluster analysis, based on the Jaccard similarity coefficient, and the Mantel test gave similar
\end{abstract}


results to the analysis of molecular variance data. Despite the low level of population structuring, these markers could be used for studying $U$. cordatus diversity, due to the high level of polymorphism.

Key words: Crab; Population genetics; Diversity; DNA amplification; Molecular markers

\section{INTRODUCTION}

The use of molecular markers in population genetics studies has proven to be decisive for shedding light on several aspects related to the biology, ecology and evolution of many organisms. Nevertheless, when choosing a specific molecular marker, one should consider not only the objective of the study but also other important aspects related to the accessibility and feasibility of the techniques. Molecular markers based on single-primer DNA amplification are an important alternative, since they can potentially amplify any genome. Among these markers, the inter simple sequence repeat (ISSR) has been used in several species due to its high level of polymorphism and reproducibility (Zietkiewicz et al., 1994; Panarari, 2006). These peculiarities are also described for another class of genetic marker, general amplification primers (GAP), based on the amplification of DNA loci flanked by sequences potentially present in any genome (Hadano et al., 1991; Telenius et al., 1992; Hang et al., 2006). They are not essentially different from RAPD markers, except for the length of the primers (RAPD primers are shorter than GAP ones). These markers, jointly, are likely to be suitable for genetic diversity studies, especially if only a basic laboratory infrastructure is available.

For any species, information on the genetic diversity is critical for sustainable management and conservation purposes. The mangrove crab Ucides cordatus, which occurs along the subtropical and tropical Atlantic coast of America, is a threatened species. It is possible that heavy exploitation, habitat destruction and occurring diseases are directly affecting the genetic diversity of crab populations (Alves et al., 2005; Boeger et al., 2007). These events can result in the collapse of this important fishery resource and cause ecological and social impacts on the ecosystem and fishing communities, respectively.

Therefore, this work aimed to evaluate the potential of an alternative nuclear marker using a single primer-based DNA amplification as a suitable and low-cost molecular tool for population-level studies in the mangrove crab U. cordatus. Parameters such as reproducibility, the number of loci, and polymorphism among populations were investigated in order to assess the genetic diversity of this species in Brazil.

\section{MATERIAL AND METHODS}

\section{Sampling}

Ucides cordatus samples $(\mathrm{N}=76)$ were collected from four different localities as depicted in Figure 1. Individuals were captured in single harvesting operations, from 2006 until 2009. Tissue samples from a segment of the last pereiopod were removed using a non-lethal method and immediately preserved in $100 \%$ ethanol. All samples were taken to the laboratory and stored at $-20^{\circ} \mathrm{C}$ until further use. 


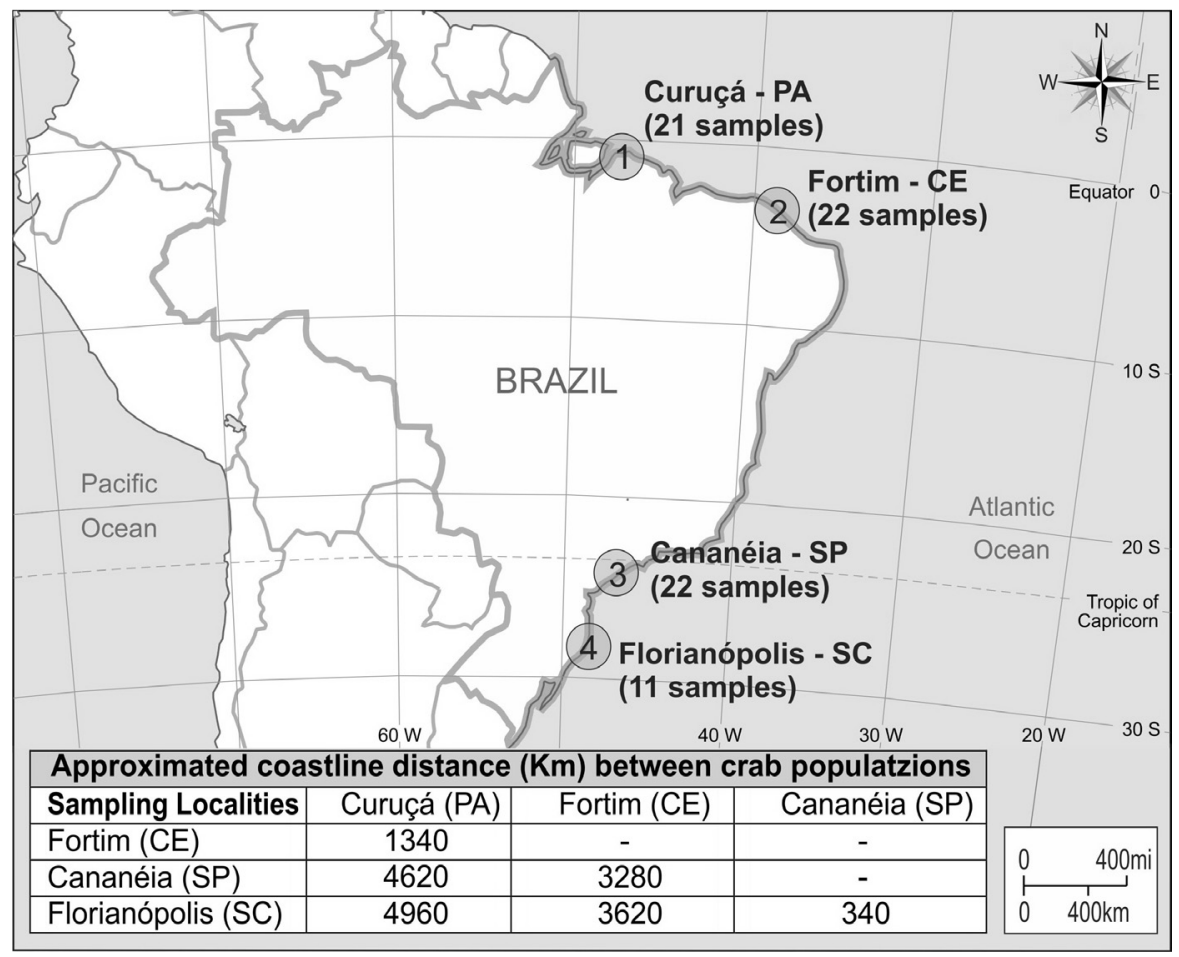

Figure 1. Map of South America, showing Brazilian coastline and the four localities where crabs were collected. The coastline distance among localities can be observed at the bottom of the figure.

\section{DNA extraction and polymerase chain reaction (PCR)}

Total genomic DNA was extracted from the muscle tissue using a phenol/chloroform-isoamyl alcohol (25:24:1, v:v:v) extraction of SDS/proteinase K digested tissue of each individual (Sambrook et al., 1989). High molecular weight DNA was isolated by ethanol precipitation and evaluated by gel electrophoresis. The extracted DNA was then amplified via PCR using the following 65 primers: a) sixty-four primers developed by the University of British Columbia (UBC, set \#9), which consisted of 55 ISSR and nine GAP primers (http:// www.michaelsmith.ubc.ca/services/NAPS/Primer_Sets); b) one ISSR primer developed by Embrapa Mid-North (Embr01 = 5'-GACAGACAGACAGACAGT-3'), randomly selected.

The potential for amplification of genomic DNA using these 65 primers was initially assessed in PCR reactions with four different DNA samples (one from each locality) and a negative control (without DNA). The calculated melting temperature $\left(\mathrm{T}_{\mathrm{m}}\right)$ of each primer was first tested as the annealing temperature $\left(\mathrm{T}_{\mathrm{a}}\right)$ in PCRs. The $\mathrm{T}_{\mathrm{m}}$ of primers ranged from $20^{\circ}$ to $69^{\circ} \mathrm{C}$. Also, the reactions were tested at $5^{\circ}$ and $10^{\circ} \mathrm{C}$ below $\mathrm{T}_{\mathrm{m}}$ and $5^{\circ} \mathrm{C}$ above $\mathrm{T}_{\mathrm{m}}$. PCR was carried out in 20- $\mu \mathrm{L}$ reaction volume containing 15-40 ng template DNA, PCR buffer ( $40 \mathrm{mM}$ Tris- $\mathrm{HCl}$ and $100 \mathrm{mM} \mathrm{KCl}$, final concentrations), $2.0 \mu \mathrm{M}$ primer, 1.5 to $4.0 \mathrm{mM} \mathrm{MgCl}_{2}$ (different concentrations were tested for each primer starting with lower concentration), $200 \mu \mathrm{M}$ of each dNTP, and 1.0 U Taq DNA polymerase (Invitrogen). Several PCR assays were performed 
with 1X Q-solution ${ }^{\mathrm{TM}}$ (Qiagen), which could improve the amplification of templates with a high degree of secondary structure. All amplifications were carried out in a Perkin Elmer thermocycler (GeneAmp PCR System 2400 ${ }^{\mathrm{TM}}$ ). The following PCR conditions were used: an initial denaturation step at $94^{\circ} \mathrm{C}$ for $1.5 \mathrm{~min}$, followed by 44 cycles with denaturation at $94^{\circ} \mathrm{C}$ for 40 $\mathrm{s}$, annealing (as per above) for $1 \mathrm{~min}$, and extension at $72^{\circ} \mathrm{C}$ for $2 \mathrm{~min}$. The final extension was performed at $72^{\circ} \mathrm{C}$ for $5 \mathrm{~min}$. The amplified fragments were electrophoresed on $2 \%$ agarose gels using 1.0X TBE buffer ( $89 \mathrm{mM}$ Tris base, $89 \mathrm{mM}$ boric acid, $2 \mathrm{mM}$ EDTA, $\mathrm{pH} 8.0$ ) and later visualized by ethidium bromide $(0.5 \mu \mathrm{g} / \mathrm{mL})$ staining and ultraviolet transillumination.

Primers were chosen according to the reproducibility of bands (loci) shown on gels (i.e., clearly separated bands with sufficient contrast and absence of smear). The selected primers were then used for genotyping of all the 76 samples captured.

\section{Data analysis and statistics}

Using direct gel analysis, the length range of amplified bands (loci) for each primer was examined. The polymorphism rate was also evaluated after counting how many polymorphic bands were present among the total number of amplified bands. In addition, the polymorphism rate was evaluated for each single population.

For statistical interpretation the PCR profiles were scored for absence (0) and presence (1) of bands across genotypes and entered into a binary matrix. The program HICKORY 1.1, which implements the Bayesian method described by Holsinger et al. (2002), was used for estimating heterozygosities $\left(H_{\mathrm{S}}\right)$ and $\theta^{\mathrm{B}}$ (a $F_{\mathrm{ST}}$ analogue) within sampling sites.

Analysis of molecular variance (AMOVA) for the four populations was carried out to determine $\Phi_{\text {ST }}$, another $\mathrm{F}_{\mathrm{ST}}$ analogue, using ARLEQUIN 3.0 (Excoffier et al., 2005). In an attempt to evaluate the reliability of the analysis, global $\Phi_{\mathrm{ST}}$ values (including all population sets) were first determined using an increasing number of loci in calculations $(3,6,9 \ldots$ up to the maximum number found), which would also indicate the minimum number of loci suitable for studies on genetic variability of the species. ARLEQUIN was also used to estimate the occurrence of isolation by distance (IBD), calculating the significance of correlations between linearized pairwise $\Phi_{\mathrm{ST}}\left[\right.$ i.e., $\left.\Phi_{\mathrm{ST}} /\left(1-\Phi_{\mathrm{ST}}\right)\right]$ between each pair of population and geographical distances (according to the one-dimension model), using the Mantel test with 1000 permutations (Mantel, 1967).

The use of different algorithms for the calculation of $\mathrm{F}_{\mathrm{ST}}$ analogues was an additional effort in order to check the reliability of the data presented by ISSR and GAP markers. Both $\theta^{\mathrm{B}}$ and $\Phi_{\mathrm{ST}}$ values were compared to each other.

The genetic similarity among samples was estimated using the software PAST according to Jaccard coefficient (Hammer et al., 2001). Cluster analysis was performed on the data set, which was applied to construct a dendrogram using the unweighted pair group method with arithmetic average (UPGMA) to determine genetic relationships between samples.

\section{RESULTS AND DISCUSSION}

Sixty-five primers were tested, but only five showed successful PCR amplification and yielded consistent and polymorphic bands (loci) (Table 1 and Figure 2). After several attempts, using different annealing temperatures and different $\mathrm{MgCl}_{2}$ concentrations, most of 
the primers showed weak amplification or a strong smear and, thus, could not be used in analysis. However, the five primers selected displayed clearly separated bands with sufficient contrast and absence of smear (Figure 2), and were therefore used for genotyping all U. cordatus samples. Even though a larger number of primers would be expected for drawing consistent conclusions on the genetic structure of the mangrove crab U. cordatus, AMOVA demonstrated that the number of loci detected was sufficient to produce statistically supported results. In fact, after 50 loci, very little variation was observed in global $\Phi_{\mathrm{ST}}$ values (Figure 3). Other studies have also found similar results, where few primers revealed many polymorphic loci (Gilbert et al., 1999). Lanham and Brennan (1998), for example, demonstrating that 16 different redcurrant (Ribes rubrum) genotypes were distinguished using only three ISSR primers.

Table 1. Selected primers with their sequences, some particular PCR profiles and the main characteristics of the
fragments amplified.
\begin{tabular}{llccccccc}
\hline Primer code & Sequence & $\mathrm{MgCl}_{2}(\mathrm{mM})$ & Adjuvant & $\mathrm{T}_{\mathrm{a}}$ & FLR (bp) & TNAL & TNPL & PR $(\%)$ \\
\hline UBC892 & 5'-TAGATCTGATATCTGAATTCCC-3' & 2.5 & Q-solution & 43 & $400-1100$ & 15 & 15 & 100.0 \\
UBC895 & 5'-AGAGTTGGTAGCTCTTGATC-3' & 4.0 & - & 42 & $300-1100$ & 16 & 12 & 75.0 \\
UBC899 & 5'-CATGGTGTGGTCATTGTTCCA-3' & 4.0 & - & 42 & $160-1000$ & 18 & 9 & 50.0 \\
UBC900 & 5'-ACTTCCCACAGGTTAACACA-3' & 4.0 & - & 42 & $300-850$ & 17 & 16 & 94.1 \\
EMBR01 & 5'-GACAGACAGACAGACAGT-3' & 4.0 & - & 48 & $350-850$ & 12 & 11 & 91.7 \\
Total & & & & & & 78 & 63 & 80.8 \\
\hline
\end{tabular}

$\mathrm{T}_{\mathrm{a}}=$ annealing temperature $\left({ }^{\circ} \mathrm{C}\right) ; \mathrm{FLR}=$ fragment length range; $\mathrm{TNAL}=$ total number of amplified loci; $\mathrm{TNPL}=$ total number of polymorphic loci; $\mathrm{PR}=$ polymorphism rate per primer $(\%)$.

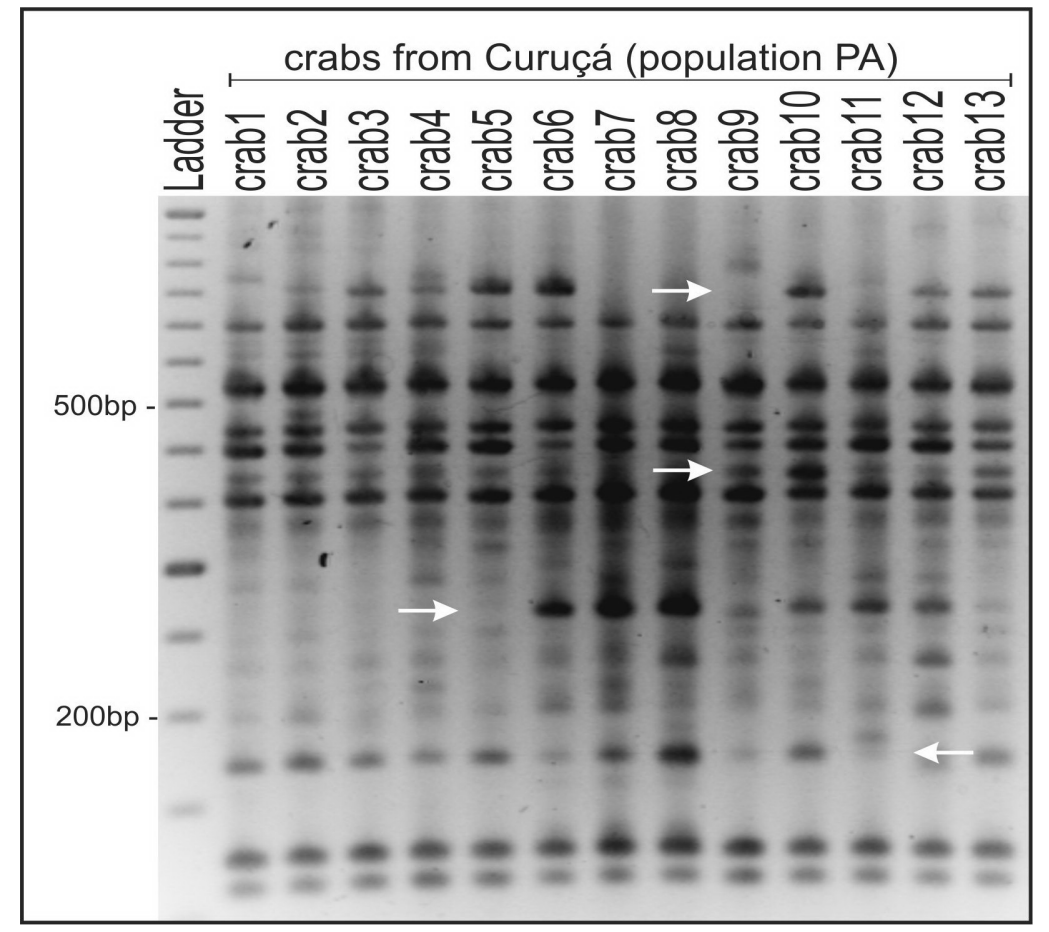

Figure 2. PCR products amplified using the primer UBC899. Some polymorphic loci can be observed among samples (arrows). 


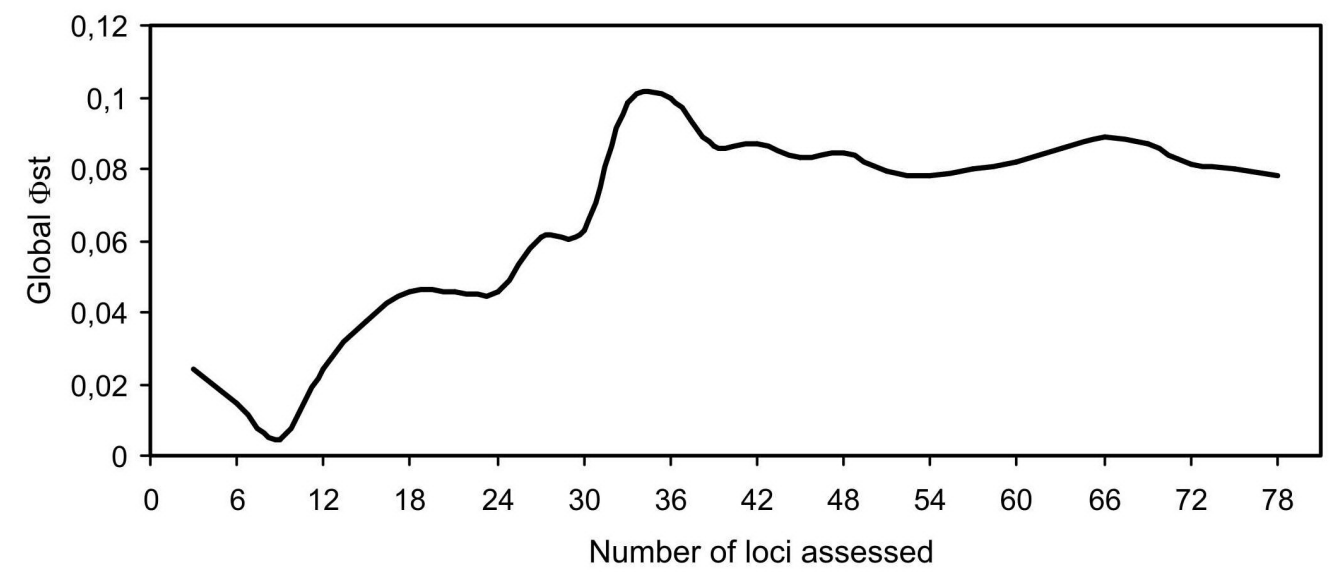

Figure 3. Range of global $\Phi_{\mathrm{ST}}$ values (for all populations) according to the number of loci assessed.

The amplified fragments obtained from a total of 76 specimens ranged between 160 and $1100 \mathrm{bp}$ (Table 1). A total of 78 loci were amplified by the five primers. The number of amplified loci for each primer varied from 12 (Embr01) to 18 (UBC 899). The overall rate of polymorphism was high $(80.8 \%)$, which indicates the potential of these primers for assessing the genetic variability of mangrove crabs (Table 1). The polymorphism rate for each isolated population was also high (ranging from 73.5 to $79.5 \%$ ), showing a high level of polymorphism within each population (Table 2). Heterozygosity (Hs) of each cohort was calculated using HICKORY and was homogeneously distributed within the surveyed area, averaging a value of 0.336 , which did not diverge considerably from that obtained for all populations analyzed as a single group (0.302, Table 2).

Table 2. Diversity estimates within populations of Ucides cordatus.
\begin{tabular}{lccccc}
\hline Locality & Sample size & TNAL & TNPL & PR (\%) & $H_{\mathrm{s}}{ }^{*}(95 \% \mathrm{CI})$ \\
\hline PA & 21 & 70 & 53 & 75.7 & $0.301(0.255-0.343)$ \\
CE & 22 & 73 & 58 & 79.5 & $0.338(0.291-0.373)$ \\
SP & 22 & 72 & 56 & 77.8 & $0.329(0.281-0.365)$ \\
SC & 11 & 68 & 50 & 73.5 & $0.377(0.312-0.428)$ \\
All pop & 76 & 63 & 80.8 & $0.302(0.264-0.305)$ \\
\hline
\end{tabular}

TNAL $=$ total number of amplified loci; TNPL $=$ total number of polymorphic loci; $\mathrm{PR}=$ polymorphism rate per population; $H_{\mathrm{S}}=$ heterozygosities $\left(H_{\mathrm{S}}\right.$ was calculated by HICKORY for isolated populations and for the whole sample set).

The geographic partitioning of the mangrove crab diversity was evaluated by the variance components, $\Phi_{\mathrm{ST}}$ and $\theta^{\mathrm{B}}$ estimations. Both $\Phi_{\mathrm{ST}}$ and $\theta^{\mathrm{B}}$ values were moderate and of similar magnitude ( 0.0780 and 0.0796 , respectively with $\mathrm{P}<0.001$ for both indices). In spite of the significance of the results, these estimates showed that the variation observed among populations did not indicate a strong genetic structure among cohorts. Most of the genetic variation found in $U$. cordatus samples was attributed to differences between individuals within populations $(92.2 \%$ of the variance). Not surprisingly, neither the cluster analysis (Figure 4) nor the Mantel test $\left(\mathrm{R}^{2}=0.011 ; \mathrm{P}=0.665\right)$ showed clear evidence of the formation of genetic groups 
associated with any pattern of differentiation by geographical distance. These data corroborate those previously obtained by Oliveira-Neto et al. (2007a,b) using RAPD, PCR-RFLP and mtDNA markers, and thus, validate the markers used in the present study as a potential tool for studying mangrove crab populations. In addition, the single primer-based DNA markers showed higher global $\Phi_{\mathrm{ST}}$ values $(0.078, \mathrm{P}<0.001)$ than those obtained with RAPD and PCRRFLP markers (-0.00036, $\mathrm{P}=0.55$ and $-0.00077, \mathrm{P}=0.58$, respectively) applied in previous studies. This shows that ISSR and GAP assessed more polymorphic loci.

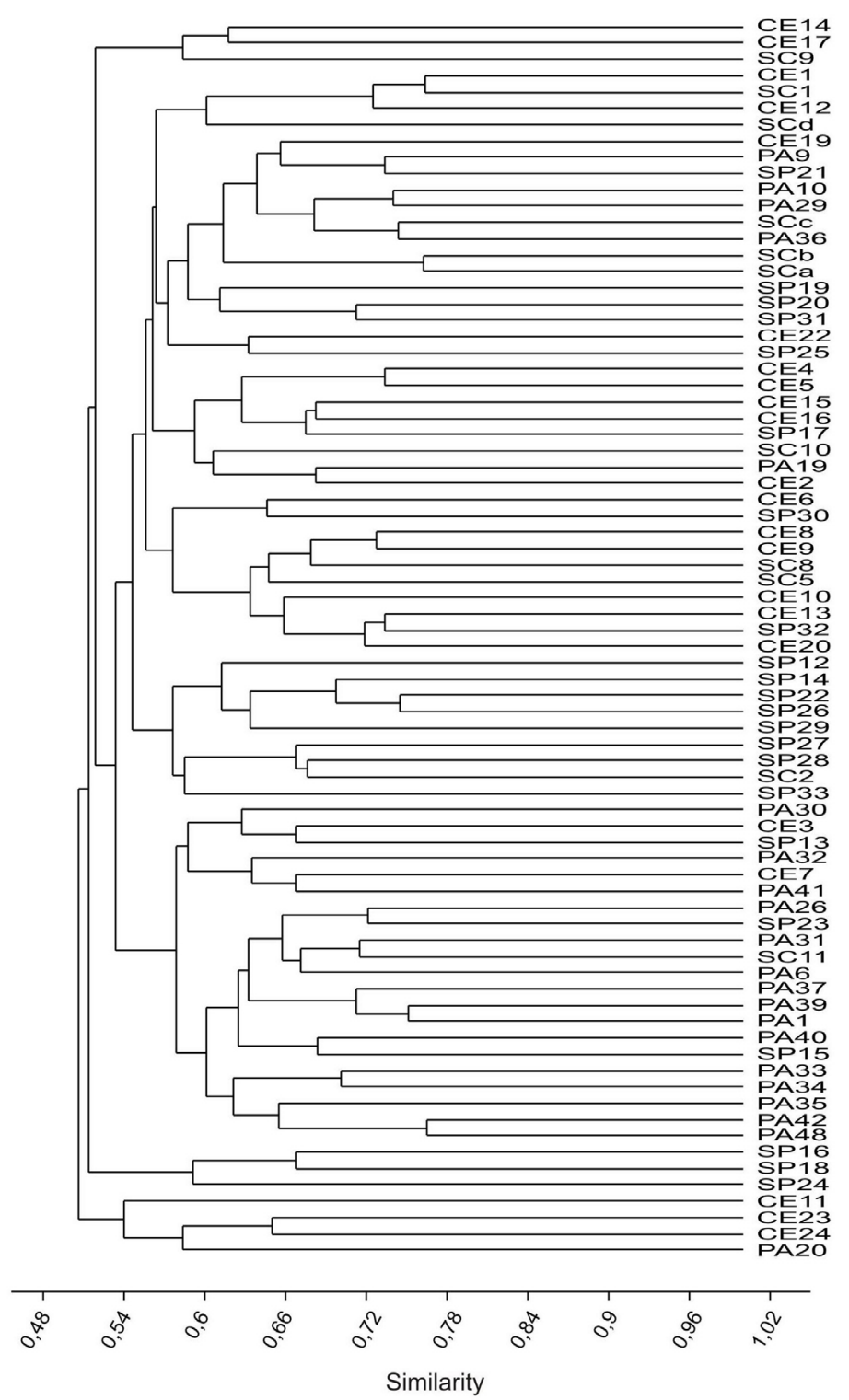

Figure 4. Cluster analysis (UPGMA, based on Jaccard index) of the samples collected in the four different localities. 
Despite the wide distribution of the mangrove crab U. cordatus, an extensive gene flow may explain the lack of genetic variation among localities in the sampled area (OliveiraNeto et al., 2007b), a possible consequence of efficient larval dispersion. The planktonic $U$. cordatus zoea I and II larvae are euryaline, but after these phases (which takes about 6 days), the last development stages do not tolerate low salinities and are exported to the open sea (Diele and Smith, 2006). Studies have also shown that the development until the megalopal stage ranges between 20 to 69 days, depending on the temperature and salinity conditions (Rodrigues and Hebling, 1989; Diele and Smith, 2006). The speed of the main Brazilian currents, the Brazil Current and the North Brazil Current, range between 0.5 to $0.6 \mathrm{~m} / \mathrm{s}$ (Evans et al., 1983 ) and 0.6 to $1.0 \mathrm{~m} / \mathrm{s}$ (Arnault et al., 1999), respectively. Thus, organisms living under the influence of these currents can be transported several thousand kilometers in only one month.

In spite of the sample size, these preliminary results introduce an important and accessible molecular tool that could be used as a primary technique for determining genetic fingerprints not only of $U$. cordatus but also of other mangrove crab populations from different species. The use of such markers can lower the cost, time and labor in research aimed at genetic diversity analysis of important fishery resources.

\section{ACKNOWLEDGMENTS}

Research supported by the Bank of Northeastern Brazil (BNB/ETENE/FUNDECI), Brazilian Agricultural Research Corporation (Embrapa) and FAPEPI/CNPq (\#20203.1010/2006-2 and \#20203.0428/2009). F.B. Britto was supported by a scholarship from the Brazilian Government (FAPEPI/CNPq DCR Scholarship Program \#350224/2006-4). The authors are grateful to the numerous people who helped in this study by sharing crab tissue samples. The anonymous reviewers are also thanked for their helpful and constructive comments, which improved the quality of the paper.

\section{REFERENCES}

Alves RR, Nishida AK and Hernandez MI (2005). Environmental perception of gatherers of the crab "caranguejo-uca" (Ucides cordatus, Decapoda, Brachyura) affecting their collection attitudes. J. Ethnobiol. Ethnomed. 1: 10.

Arnault S, Bourles B, Gouriou Y and Chuchla R (1999). Intercomparison of upper layer circulation of the western equatorial Atlantic Ocean: In situ and satellite data. J. Geophysical Res. 104: 171-194.

Boeger WA, Pie MR, Vicente V, Ostrensky A, et al. (2007). Histopathology of the mangrove land crab Ucides cordatus (Ocypodidae) affected by lethargic crab disease. Dis. Aquat. Organ. 78: 73-81.

Diele K and Smith DJB (2006). Salinity tolerance of northern Brazilian mangrove crab larvae, Ucides cordatus (Ocypodidae): Necessity for larval export? Estuar. Coast Shelf Sci. 68: 600-608.

Evans DL, Signorini SR and Miranda LB (1983). A note on the transport of the Brazil Current. J. Phys. Oceanogr. 13: 1732-1738.

Excoffier L, Laval G and Schneider S (2005). Arlequin (version 3.0): an integrated software package for population genetics data analysis. Evol. Bioinform. Online 1: 47-50.

Gilbert JE, Lewis RV, Wilkinson MJ and Caligari PDS (1999). Developing an appropriate strategy to assess genetic variability in plant germplasm collections. Theor. Appl. Genet. 98: 1125-1131.

Hadano S, Watanabe M, Yokoi H, Kogi M, et al. (1991). Laser microdissection and single unique primer PCR allow generation of regional chromosome DNA clones from a single human chromosome. Genomics 11: 364-373.

Hammer O, Harper DAT and Ryan PD (2001). Past: Paleontological statistics software package for education and data analaysis. Palaeontol. Electron. 4: 1-9.

Hang A, Burton CS and Bockelman H (2006). Characterization of wild wheat (Aegilops L.) and wild barley (Hordeum L.) germplasm using intersimple sequence repeat (ISSR) and general DNA primers. Plant. Genet. Resour. Newsl. 
147: $25-28$.

Holsinger KE, Lewis PO and Dey DK (2002). A Bayesian approach to inferring population structure from dominant markers. Mol. Ecol. 11: 1157-1164.

Lanham PG and Brennan RM (1998). Characterization of the genetic resources of redcurrant (Ribes rubrum: subg. Ribesia) using anchored microsatellite markers. Theor. Appl. Genet. 96: 917-921.

Mantel N (1967). The detection of disease clustering and a generalized regression approach. Cancer Res. 27: 209-220.

Oliveira-Neto JF, Boeger WA, Pie MR and Ostrensky A (2007a). Genetic structure of populations of the mangrove crab Ucides cordatus (Decapoda: Ocypodidae) at local and regional scales. Hydrobiologia 583: 69-76.

Oliveira-Neto JF, Pie MR, Boeger WA and Ostrensky A (2007b). Population genetics and evolutionary demography of Ucides cordatus (Decapoda: Ocypodidae). Mar. Ecol. 28: 460-469.

Panarari RS (2006). Variabilidade Genética, Evidenciada por Marcadores Nucleares e do Genoma Mitocondrial, de Espécies do Gênero Brycon (Characiformes: Characidae) de Três Bacias Hidrográficas. Doctoral thesis, Universidade Estadual de Maringá, Maringá.

Rodrigues MD and Hebling NJ (1989). Ucides cordatus (Linnaeus, 1763) (Crustacea, Decapoda). Complete larval development under laboratory conditions and its systematic position. Rev. Bras. Zool. 6: 147-166.

Sambrook J, Fritsch EF and Maniatis T (1989). Molecular Cloning. A Laboratory Manual. 2nd edn. Cold Spring Harbor Laboratory Press, Cold Spring Harbor.

Telenius H, Carter NP, Bebb CE, Nordenskjold M, et al. (1992). Degenerate oligonucleotide-primed PCR: general amplification of target DNA by a single degenerate primer. Genomics 13: 718-725.

Zietkiewicz E, Rafalski A and Labuda D (1994). Genome fingerprinting by simple sequence repeat (SSR)-anchored polymerase chain reaction amplification. Genomics 20: 176-183. 